\title{
IMPLICAÇÕES NA SAÚDE MENTAL DE IDOSOS DIANTE DO CONTEXTO PANDÊMICO DA COVID-19
}

\section{IMPLICATIONS FOR THE MENTAL HEALTH OF THE ELDERLY IN THE CONTEXT OF THE COVID-19 PANDEMIC}

\author{
Alex do Nascimento Alves ${ }^{1} *$ Isabella Medeiros de Oliveira Magalhães ${ }^{2}$
}

Caro editor,

A Covid-19 (Coronavirus disease - 19), desde a sua origem na cidade de Wuhan, na China, em dezembro de 2019, sofreu um aumento exponencial de casos no mundo, fato este que levou a Organização Mundial da Saúde (OMS) a declarar, no dia 30 de Janeiro de 2020, o surto do novo coronavírus (2019-nCov) como uma Emergência de Saúde Pública de Importância Internacional (ESPII) ${ }^{(1)}$.

Objetivando minimizar os efeitos desta, que se constitui como das maiores pandemias já vistas, foram implementadas várias medidas, destacando-se o distanciamento social, a fim mitigar o avanço do número de casos e o eventual aumento da demanda por serviços de saúde, que poderia induzi-lo ao colapso, impedindo a resposta dos serviços às necessidades de saúde da população( ${ }^{(2)}$.

A pandemia trouxe consigo diversos fatores que podem favorecer alterações na condição de saúde mental, a exemplo da desinformação ou das notícias falsas, do excesso de informação, do distanciamento social e suas repercussões inclusive na empregabilidade e sustento de muitos. Considera-se também impactos como os danos econômicos e a perda de entes queridos. Em suma, as situações supracitadas podem favorecer agravos ou surgimento de condições relacionadas à saúde mental ${ }^{(3)}$.

Dentre os grupos vulneráveis ao desenvolvimento de alterações na condição de saúde

\footnotetext{
${ }^{1}$ Enfermeiro. Mestre em Saúde Pública. Universidade Estadual da Paraíba (UEPB). Departamento de Enfermagem. Campina Grande-PB, Brasil. ORCID: https://orcid.org/0000-0001-6814-0710. E-mail: alexi.enf@gmail.com

${ }^{2}$ Enfermeira. Mestre em Saúde Pública. Doutoranda do Programa Associado de Pós-graduação em Enfermagem UPE/UEPB (PAPGEnf). Campina Grande, Paraíba, Brasil. ORCID: https://orcid.org/0000-0003-0181-480X E-mail: bellaa.medeiros@gmail.com
} 


\section{CARTA AO EDITOR}

mental, encontram-se os idosos, com destaque para àqueles que já possuem algum comprometimento cognitivo, uma vez que, perdas cognitivas, afetivas e o distanciamento podem ser fatores de risco para o desencadeamento de distúrbios mentais e para produção de impacto direto na qualidade de vida ${ }^{(4)}$.

Outrossim, destaca-se que no contexto da pandemia atual, a população idosa está inclusa no grupo de risco para o contágio com a Covid-19, fator que pode ser considerado como de risco para o desenvolvimento de alterações emocionais motivadas pela ansiedade e o medo de contaminação e também do desconhecido, apresentando-se como uma situação estressora durante o período de distanciamento, podendo provocar mudanças na condição de saúde mental, assim como agravar as condições daqueles que por ventura já são acometidos ${ }^{(5)}$.

Grande parte da população pode ser impactada de alguma forma pela Covid-19, seja a curto ou a longo prazo. Considera-se importante, portanto, implementar ações que incluam cuidados de saúde mental ao idoso, como acesso à medicações e aconselhamento psicológico durante a pandemia ${ }^{(4)}$. Salienta-se a importância de assegurar à essa população informações precisas como forma de conter o medo e a ansiedade, além de disponibilizar canais de escuta que tragam informações práticas sobre como enfrentar e gerenciar as situações de estresse ${ }^{(5)}$.

Enfatiza-se ainda a necessidade de um olhar a este grupo no que refere ao suporte e apoio familiar, visto que- o distanciamento social não justifica e nem caracteriza o abandono, necessitando a família, em conjunto com o idoso, refletir e discutir as estratégias necessárias para o oportuno momento ${ }^{(6)}$.

Por fim, a pandemia trouxe à tona a necessidade do Cuidado Gerontológico de forma qualificada e segura, também da importante ação de educação e capacitação profissional para atender as demandas do público alvo, respeitando a singularidade de cada idoso e a atenção integral à saúde, não infringindo os princípios doutrinários do Sistema Único de Saúde (SUS) ${ }^{(6)}$.

Sendo assim, torna-se necessário maior atenção por parte dos entes públicos em relação à essa população no contexto atual, objetivando diminuir os efeitos danosos da Covid-19, com vistas a reduzir o impacto das alterações psicológicas nessa população, além de suavizar o ônus financeiro no custeio de tratamentos em função de alterações na condição de saúde mental. 


\section{REFERÊNCIAS}

1. Organização Pan-Americana da Saúde. OMS declara emergência de Saúde Pública de importância internacional por surto de novo coronavírus. Brasília (DF): OPAS; 2020.

2. Nunes J. The COVID-19 pandemic: securitization, neoliberal crisis, and global vulnerabilization. Cad. Saúde Pública [Internet]. 2020 [citado em 16 jun 2020]; 36(5): e00063120. https://doi.org/10.1590/0102-311x00063120.

3. Ransing R, Adiukwu F, Pereira-Sanchez V, Ramalho R, Orsolini L, Teixeira ALS, et al. Mental Health Interventions during the COVID-19 Pandemic: A Conceptual Framework by Early Career Psychiatrists. Asian J Psychiatry [Internet]. 2020 [citado em 16 jun 2020]; 51:102085. https://doi.org/10.1016/j.ajp.2020.102085.

4. Castro-de-Araujo LFS, Machado DB. Impact of COVID-19 on mental health in a Low and Middle-Income Country. Ciênc. Saúde Coletiva [Internet]. 2020 [16 jun 2020]; 25(Suppl 1): 2457-2460. https://doi.org/10.1590/1413-81232020256.1.10932020.

5. Brooks SK, Webster RK, Smith LE, Woodland L, Wessely S, Greenberg N, et al. The psychological impact of quarantine and how to reduce it: rapid review of the evidence. The Lancet [Internet]. 2020 [citado em 16 jun 2020]; 395(10227): 912-20. https://doi.org/10.1016/S0140-6736(20)30460-8.

6. Hammerschmidt KSA, Santana RF. Saúde do idoso em tempos de pandemia covid-19. Cogitare Enfermagem [Internet]. 2020 [citado em 29 jun 2020]; 25(e72849). http://dx.doi.org/10.5380/ce.v25i0.72849.

Recebido: 2020-06-30

Aceito: 2020-07-31 